\title{
Sexual health of very young adolescents in South Western Uganda: a cross-sectional assessment of sexual knowledge and behavior
}

Elizabeth Kemigisha ${ }^{1,2^{*}}$, Katharine Bruce ${ }^{1}$, Viola N. Nyakato ${ }^{1}$, Gad Ndaruhutse Ruzaaza ${ }^{1}$, Anna B. Ninsiima ${ }^{3}$, Wendo Mlahagwa ${ }^{1}$, Els Leye ${ }^{2}$, Gily Coene ${ }^{3}$ and Kristien Michielsen ${ }^{2}$

\begin{abstract}
Background: In most Sub-Saharan African countries, little is known about young adolescents' sexual and reproductive health $(\mathrm{SRH})$. Though some efforts have been made to understand and improve SRH of older adolescents, very young adolescents (VYAs) are often overlooked, and little is known about their sexual knowledge and behaviors. The goal of this study was to describe SRH knowledge, information-seeking, and sexual behavior of VYAs in Uganda.

Methods: A cross-sectional survey was administered in 33 primary schools in June and July of 2016. Trained interviewers administered surveys to adolescents ages 10-14 regarding SRH knowledge, information-seeking, sexual behavior, and relevant covariates. Continuous variables were summarized as means (SD) or medians (IQR) whereas categorical variables were summarized as proportions (percentages).

Results: A total of 1096 adolescents were included in this analysis, $81.8 \%$ of which were from rural areas, with a median age of 12. Regarding sexually transmitted infections (STIs) knowledge; 95\% knew HIV while 37\% knew other STIs apart from HIV. Although 47\% knew at least one way in which HIV is acquired only $8 \%$ knew at least four ways. Regarding contraceptive knowledge, 56\% mentioned at least one modern method of preventing pregnancy (condoms, pills, intrauterine devices, implants, or injections). The majority (85\%) of VYAs reported accessing SRH information in the media with 35\% reporting accessing media with sexual content while $10 \%$ vs $22 \%$ consulted their father or mother respectively and 31\% a school source. At least $7.6 \%$ of VYAs had ever had sexual intercourse, $90 \%$ of which were not using any protection.

Conclusion: Comprehensive SRH knowledge was low among VYAs in this study. Media remains an important source of information for SRH for this age group though it may be misused as some adolescents reported accessing sexual content that may be inappropriate. A large proportion of sexually active VYAs reported sexual risky behaviors. This study highlights the need for an accurate and more comprehensive SRH education approach for VYAs in Uganda at an opportune age before the majority engage in sexual behavior.
\end{abstract}

Keywords: Young adolescents, Sexuality, Uganda

\footnotetext{
* Correspondence: ekemigisha@must.ac.ug

${ }^{1}$ Mbarara University of Science and Technology, P.O. Box 1410, Mbarara,

Uganda

${ }^{2}$ International Centre for Reproductive Health, Faculty of Medicine and

Health Sciences, Ghent University, Ghent, Belgium

Full list of author information is available at the end of the article
}

(c) The Author(s). 2018 Open Access This article is distributed under the terms of the Creative Commons Attribution 4.0 International License (http://creativecommons.org/licenses/by/4.0/), which permits unrestricted use, distribution, and reproduction in any medium, provided you give appropriate credit to the original author(s) and the source, provide a link to the Creative Commons license, and indicate if changes were made. The Creative Commons Public Domain Dedication waiver (http://creativecommons.org/publicdomain/zero/1.0/) applies to the data made available in this article, unless otherwise stated. 


\section{Plain English summary}

Uganda has the second youngest population in the world, with high rates of sexually transmitted diseases and adolescent pregnancy. Access to sexual and reproductive health (SRH) information and resources is a challenge, especially for very young adolescents (VYAs) aged 10-14. The goal of this study is to assess levels of SRH knowledge, SRH information seeking and sexual behavior among VYAs. We found that most students are aware of HIV, but few have detailed knowledge of how HIV is acquired, what other STIs exist, and what methods of pregnancy prevention are available. Seven percent of VYAs were already sexually active with most of them not using any form of protection such as condoms. The majority of VYAs had been exposed to SRH information in the media (television, radio or newspapers) with at least one third of them accessing media with sexual content, while far fewer had received such information in schools or from their parents. This study highlights the importance of implementing school-based $\mathrm{SRH}$ education at a young age. Because the majority of VYAs are not yet sexually active, $\mathrm{SRH}$ interventions in this age group may be more effective than those in older adolescents in delaying sexual onset and decreasing risky sexual behavior. Furthermore, because these students are already being exposed to sexual information in the media, it is important for schools and parents to provide accurate information that helps students to reflect more critically on SRH information in media sources.

\section{Background}

With a median age of just 15, Uganda has the second youngest population in the world [1]. Over half of the population is the under age of 18 years [2]. This youthful population presents unique challenges, especially with regard to sexual and reproductive health (SRH). Uganda's 2016 Demographic and Health Survey (DHS) found that $24.8 \%$ of girls ages $15-19$ had already begun childbearing, which was as high as $53.9 \%$ among girls age 19 [3]. Uganda has one of the ten highest HIV prevalence rates in the world at $6.2 \%(4.7 \%$ among males and $7.6 \%$ among females) $[4,5]$. Despite great initial success in decreasing HIV prevalence and incidence throughout the 1990s and early 2000s [6], HIV/AIDS remains the leading cause of death in Uganda [7], and the majority of new infections occur among adolescent women [3]. In this young population, comprehensive access to sexual and reproductive health knowledge and services is of upmost importance.

Access to $\mathrm{SRH}$ information and prevention services remains a challenge in most developing countries, including Uganda. The 2016 DHS found that only $40 \%$ of Ugandan adolescents ages 15-19 years have comprehensive HIV prevention knowledge [3]. A study among girls in Ugandan primary schools found low knowledge of menstruation and menstrual hygiene [8]. Inadequate SRH knowledge creates anxiety and shame, especially at the beginning of puberty [9]. While there is little data available on SRH outcomes among VYAs in Uganda, poor reproductive health outcomes become especially evident in late adolescence. A study among university students found high non-use of contraception, inconsistent condom use and low knowledge of proper condom use, especially among females and those who had early sexual debut $[10,11]$. It is possible that intervening in early adolescence could mitigate adverse outcomes in older adolescence.

Despite these challenges, there has been a lot of pushback on SRH education in Uganda from parents, teachers, and even Members of Parliament (MPs), who feel that teaching these topics in schools will erode Uganda's culture and morality [12]. In 2016, the Ministry of Gender, Labor and Social Development banned sexuality education in schools [13]. The Ministry of Education and Sports recently released new national guidelines on sexuality education, but these guidelines are not comprehensive, they emphasize abstinence, and the future of their implementation is still unclear [14]. With no standardized SRH curriculum in schools and ongoing religious and political pushback on its relevance and appropriateness, adolescents in Uganda are left with few options to seek SRH information.

Following evidence on the proven benefits of comprehensive sexuality education in diverse settings [15], UNESCO recently released guidelines outlining recommendations for comprehensive sexuality education [16]. However, most of the existing SRH interventions in low and middle income countries, as well as most of the existing research, focus on older adolescents [15]. SRH needs of very young adolescents (VYAs), those aged 1014 years, are often neglected in research and action [1719] and there are many gaps in understanding SRH of young adolescents, especially in Sub-Saharan Africa (SSA) [20, 21]. This younger age group may be the ideal target for SRH interventions, as their behaviors and norms are less rigid [22]. Due to the fact that the majority of VYAs in Uganda are not yet sexually active [23], they are more susceptible to behavioral interventions than their older peers who have already started engaging in risky sexual behaviors. Bankole et al., 2007 found that $11 \%$ of Ugandan adolescents ages 12-14 are already sexually active [23], showing that SRH information is indeed relevant for this young age group, who are beginning to be exposed to SRH risks. Furthermore, research by Kemigisha et al., 2018 on Ugandan VYAs found that inequitable norms around gender and sexuality increase with age [24]. Harmful gender norms surrounding sexuality, consent and decision-making exacerbate SRH risks 
for boys as well as girls [25]. Interventions should target adolescents at a young age, before they have already developed harmful norms about gender and sex.

The goal of this study is to investigate the current status of sexual behavior, SRH knowledge, and information-seeking behaviors of adolescents ages 10-14 in Uganda. It aims to fill the gap in the literature regarding the SRH of VYAs in Uganda. This information should guide the development and implementation of educational SRH interventions across the country.

\section{Methods}

\section{Study design and setting}

This paper presents the results of a cross-sectional survey of very young adolescents in primary schools in Mbarara district of South Western Uganda. This data was collected as the baseline of a cluster randomized trial to evaluate the implementation and effectiveness of a comprehensive sexuality education program in primary schools. According to the 2015 District Education reports, Mbarara has a total of 248 primary schools with an estimated primary school enrolment of 80,924 [26].

\section{Study population and selection of participants}

Participant eligibility criteria included being $10-14$ years old and in primary level 5 or 6 of education from rural and urban schools within Mbarara district. The final sample size included 1096 adolescents from 33 schools in both urban and rural settings. A list of primary schools in Mbarara was available in district records. We eliminated schools that had no upper classes (primary 5 to 7), and schools that offer unique services, including one school for children with hearing impairments and one school for children with visual impairments. The remaining schools were entered into an Excel spreadsheet and a formula was developed to randomly select the required 33 schools for the study. A second Excel formula was used to randomly assign each of the 33 schools to the treatment or control arm. Research assistants (RAs) selected the final sample of students in each school from class registration lists using systematic sampling methods and substituting pupils who were absent on the day that data was collected.

\section{Data collection}

The data were collected between June and July 2016. Standardized closed surveys were administered by trained RAs and were crosschecked by the onsite investigator and research monitors and cleaned for any errors. All RAs were fluent in both English and Runyankole (the local language) and surveys were administered based on each students' preference. Responses to all questions were recorded and coded either using scales or binary yes/no questions, with the option to refrain from responding. Additionally, questions that assessed pupils' knowledge included the option to respond with "I do not know". Anonymity was maintained throughout the study and participants' responses were deidentified.

\section{Definitions for outcome variables}

Sexual behavior was measured starting from a screening question: "have you ever been to a secret place alone with a friend of the opposite sex?" If the answer to this question was yes, further questions were asked regarding sexual experiences. These included "Did you ever kiss on the lips?", "Did you or your friend ever touch your private parts?", "Have you ever had sex?" "How old were you when you first had sex?", "What method did you use to prevent HIV/AIDS or STIs?" and "Were you willing to have sex the first time you did?"

Sexual and reproductive health knowledge was measured based on knowledge of puberty, HIV/STIs and pregnancy prevention. This included knowledge on how HIV/AIDS can be acquired, types of common Sexually Transmitted Infections, knowledge of pubertal changes in boys (such as having beards, deep voice etc.) and in girls (such as increase in breast size, having pubic or axillary hair etc.), and knowledge about ways to prevent pregnancy (such as abstinence, condom use or any other type of contraceptive).

Sources of Information on SRH were assessed. We asked students if they had sought SRH information from their mother, father, a school source, a community health facility and/or mass media sources. Media was further categorized into seeking information on SRH topics or sexual content.

Data was collected on socio-demographic variables such as age in years, pubertal stage, gender, religion, socio-economic status (assessed as a sum of the score for best water source, housing possessions and pupil possessions such as shoes or school uniform pairs), whether the school was located in rural or urban area and whether one, both or neither parents were alive.

\section{Statistical analyses}

Data was double entered into Epi-data 3.1 (EpiData, Odense, Denmark). The data utilized in this analysis represent the baseline data of a cluster randomized control trial evaluating the effectiveness of a Comprehensive Sexuality Education intervention. Based on an intra-class correlation calculated in a pilot test among 105 VYAs and an estimated drop-out rate of $20 \%$, we determined that a minimum sample size of 1100 students was needed to measure a $10 \%$ score difference in outcomes between baseline and endline among the intervention vs control groups with a power of $90 \%$. Data analysis was done using Stata ${ }^{\circ}$ (College Station, Texas, USA). Continuous variables were summarized as means (SD) or 
medians (IQR) whereas categorical variables were summarized as proportions (percentages). In addition, a bivariate analysis among categorical variables was made using chi square. All analyses were stratified by gender. A $p$-value of less than 0.05 was considered a significant association.

\section{Results}

\section{Description of participants}

A total of 1096 pupils were interviewed between June and July 2016. The median age was 12 (IQR 11, 13) years and $58 \%$ were female. Over $80 \%$ of the study population were from rural areas and over $80 \%$ of the pupils had both parents alive. Twenty-nine percent were ranked as having a high socio-economic score, $47 \%$ ranked medium and $24 \%$ ranked low (Table 1). The majority of pupils had achieved some form of puberty, with 90\% beyond (self-assessed) tanner stage 1 (i.e. beyond normal size of penis of $3 \mathrm{~cm} /$ testicular volume of $1.5 \mathrm{ml}$ in boys or lack of glandular tissue or no areola enlargement in girls and no pubic hair in both) and about half were at tanner stage 2 (i.e. showing early signs of breast, bud development or testicular enlargement with pubic hair). About 26\% of the girls had started menstruation and $23 \%$ of the boys mentioned they had experienced wet dreams.

\section{Sexual health knowledge}

Regarding knowledge about puberty, $27.9 \%$ vs $12.3 \%$ of the respondents knew at least 3 of 6 physical changes in

Table 1 Socio-demographic characteristics of the participants by gender

\begin{tabular}{|c|c|c|c|c|}
\hline & Overall, n (\%) & Male $\mathrm{n}(\%)$ & Female $\mathrm{n}(\%)$ & $p$-value \\
\hline \multicolumn{5}{|l|}{ Gender } \\
\hline Boys & $460(42.0)$ & & & \\
\hline Girls & $636(58.0)$ & & & \\
\hline Age in years, median (IQR) & $12(11,13)$ & & & \\
\hline \multicolumn{5}{|l|}{ Pubertal age (Tanner 1-5) } \\
\hline Tanner 1 & $130(11.9)$ & $49(10.6)$ & $81(12.7)$ & 1 \\
\hline Tanner 2 & $379(34.6)$ & $168(36.5)$ & $211(33.2)$ & \\
\hline Tanner 3 & $487(44.4)$ & $216(47.1)$ & $271(42.6)$ & \\
\hline Tanner 4 or 5 & $100(9.1)$ & $27(5.8)$ & $73(11.5)$ & 0.007 \\
\hline Ever experienced menstruation (female only) & $155(25.9)$ & - & $155(25.9)$ & NA \\
\hline Ever experience wet dreams (male only) & $101(22.5)$ & $101(22.5)$ & - & NA \\
\hline \multicolumn{5}{|l|}{ Education level } \\
\hline$=$ Primary 5 only & $563(51.4)$ & $240(52.2)$ & $323(50.8)$ & \\
\hline$=$ Primary 6 only & $533(48.6)$ & $220(47.8)$ & $313(49.2)$ & 0.650 \\
\hline \multicolumn{5}{|l|}{ Socio economic status ${ }^{a}$} \\
\hline Low & $315(29.0)$ & $128(28.2)$ & $187(29.6)$ & \\
\hline Medium & $511(47.1)$ & $215(47.4)$ & $296(46.8)$ & \\
\hline High & $260(23.9)$ & $111(24.4)$ & $149(23.6)$ & 0.871 \\
\hline \multicolumn{5}{|l|}{ Religion } \\
\hline Catholic & $405(37.1)$ & $165(36.0)$ & $240(37.8)$ & \\
\hline Anglican & $507(46.4)$ & $215(46.9)$ & $292(46.0)$ & \\
\hline Moslem & $101(9.2)$ & $48(10.5)$ & $53(8.4)$ & \\
\hline Other & $80(7.3)$ & $30(6.6)$ & $50(7.8)$ & 0.527 \\
\hline \multicolumn{5}{|l|}{ Location of school } \\
\hline Rural & $896(81.8)$ & $368(80)$ & $529(83.2)$ & \\
\hline Urban & 199 (18.2) & $92(20)$ & $107(16.8)$ & 0.178 \\
\hline \multicolumn{5}{|l|}{ Number of parents alive } \\
\hline Both alive & $905(82.6)$ & $378(82.2)$ & $527(82.9)$ & \\
\hline None/Single parent & $124(17.4)$ & $82(17.8)$ & $109(17.1)$ & 0.767 \\
\hline
\end{tabular}


puberty in boys vs 4 of 7 changes in girls respectively. A majority of respondents (95\%) knew HIV is an STI and $37 \%$ knew other STIs apart from HIV. Although 47\% knew at least one way in which HIV may be acquired, only $8 \%$ knew at least 4 methods by which HIV is acquired. Regarding contraceptive knowledge, 59\% mentioned abstinence, 56\% mentioned any of the more effective methods of preventing pregnancy (condoms, hormonal or surgical methods), and 3\% knew natural methods for contraception. More boys than girls knew of any effective ways to prevent pregnancy and the difference was significant (Table 2).

\section{Sources of SRH information}

A total of $85 \%$ of VYAs reported accessing SRH information through radio or television media. In addition $35.5 \%$ had access to media with sexual content via mobile device/television, and $44.5 \%$ accessed sexual content in print media (newspapers and magazines). More boys than girls watched visual media with sexual content. A total of $31.7 \%$ reported seeking SRH information from a source at school. Only $22.3 \%$ and $9.9 \%$ had discussions about love or sex with their mother or father respectively. Pupils were more likely to communicate with a parent of their same gender, meaning more boys communicated with fathers and more girls communicated with mothers (Table 3).

\section{Sexual behaviors}

A total of $15.1 \%$ respondents had ever been in a secluded place with a girlfriend or boyfriend; $3.1 \%$ had kissed, $10.5 \%$ had either touched or been touched by a boyfriend or girlfriend in the genital area, and $7.6 \%$ had had sexual intercourse. Overall, more boys than girls reported having experienced any of these forms of sexual behavior. Of those who were sexually active, only $9.6 \%$ used condoms the first time they had sex. Of those who were not sexually active, $11.3 \%$ reported they felt pressured to have sex, of which $6.1 \%$ were boys and $3.9 \%$ were girls (Table 4).

\section{Discussion}

This study describes the sexual behavior, sexual health knowledge, and information seeking behavior of VYAs in Uganda, in an effort to inform interventions related to adolescent SRH. We found that 7\% of adolescents were sexually active, and that a majority of these were not using condoms. Detailed SRH knowledge on HIV transmission, types of STIs and contraception was low. Furthermore, media was the most utilized source for SRH information, while school and parental sources were underutilized.

In Uganda, there is a lot of pushback against SRH education from many key stakeholders, including political, religious and cultural leaders, who feel that these topics are inappropriate for children and should not be taught in schools [12]. There are no clear guidelines on what, when, and in what setting SRH information should be disseminated to students [27]. However, this study shows that regardless of whether these topics are taught in schools, adolescents receive information on sex and relationships at a young age. We found that the majority (85.2\%) of VYAs had been exposed to media on SRH topics with over one third accessing media with sexual content. More boys than girls had seen a movie or show

Table 2 Level of knowledge on Sexual and Reproductive Health by gender among Very Young Adolescents in South Western

\begin{tabular}{|c|c|c|c|c|c|}
\hline Characteristic & Total & Male & Female & Chi & $p$ value \\
\hline \multicolumn{6}{|l|}{ Knowledge on pubertal signs } \\
\hline Pubertal signs in boys (at least 3/6) & $305(27.9)$ & $158(34.4)$ & $147(23.2)$ & 16.58 & $<0.001$ \\
\hline Pubertal signs in girls (at least $4 / 7$ ) & $134(12.3)$ & $56(12.2)$ & $78(12.4)$ & 0.09 & $<0.926$ \\
\hline \multicolumn{6}{|l|}{ Knowledge on STIS } \\
\hline Knows HIV as an STI & $1037(95.1)$ & $441(96.5)$ & $596(94.2)$ & 3.15 & 0.076 \\
\hline Knows any STI apart from HIV & $402(36.7)$ & $183(39.8)$ & $219(34.4)$ & 3.29 & 0.07 \\
\hline \multicolumn{6}{|l|}{ Knowledge of HIV transmission } \\
\hline Knows at least 1 way of HIV acquisition & $516(47.1)$ & $218(47.4)$ & $298(46.9)$ & 0.03 & 0.861 \\
\hline Knows 4 ways of HIV acquisition & $86(7.9)$ & $42(9.1)$ & $44(6.9)$ & 1.81 & 0.179 \\
\hline Knows a person who looks healthy can still have HIV & $710(65.3)$ & $350(76.8)$ & $360(57.1)$ & 54.05 & $<0.001$ \\
\hline \multicolumn{6}{|l|}{ Knowledge on pregnancy prevention } \\
\hline Knows abstinence & $627(59.0 \%)$ & $264(58.9)$ & $363(59.1)$ & 0.004 & 0.95 \\
\hline Knows natural methods & $33(3.1 \%)$ & $21(4.7)$ & $12(2.0)$ & 6.43 & 0.01 \\
\hline Knows more effective methods & $592(55.8 \%)$ & $297(66.4)$ & $295(48.0)$ & 35.50 & $<0.001$ \\
\hline
\end{tabular}


Table 3 Sources of information on Sexual and Reproductive Health for Very Young Adolescents in SW Uganda

\begin{tabular}{|c|c|c|c|c|c|}
\hline Characteristic & Total & Male & Female & Chi & $p$ value \\
\hline \multicolumn{6}{|l|}{ Ever sought information on SRH } \\
\hline Father & $82(9.9)$ & $44(11.5)$ & $38(7.2)$ & 4.97 & 0.03 \\
\hline Mother & $222(22.3)$ & $58(13.9)$ & $164(28.4)$ & 29.39 & $<0.001$ \\
\hline School source (of 791 who were aware of services) & $251(31.7)$ & $57(19.9)$ & $194(38.7)$ & 28.80 & $<0.001$ \\
\hline Community health facility & $61(5.6)$ & $29(6.3)$ & $32(5.0)$ & 1.09 & 0.58 \\
\hline Any mass media with educative SRH topics & $923(85.2)$ & $396(87.2)$ & $527(83.7)$ & 2.66 & 0.10 \\
\hline Ever watched a movie or show with sexual content & $389(35.5)$ & $191(41.5)$ & $198(31.2)$ & 12.45 & $<0.001$ \\
\hline Ever read a newspaper or magazine describing sexual content & $487(44.5)$ & $220(47.9)$ & $267(42.1)$ & 3.73 & 0.05 \\
\hline
\end{tabular}

with sexual content. However, far fewer adolescents received this information in school or from their parents.

Much of the SRH information in the media that adolescents are exposed to may be inaccurate or misleading $[28,29]$. Although some public health institutions in Uganda use media to provide adolescents with accurate and relevant SRH information [30,31], it is hard for adolescents to determine which sources are accurate and which are not $[28,29]$. Moreover, media with sexual content has been associated with early sexual debut among adolescents in Africa [32]. Findings from a qualitative study in Uganda indicate use of media with sexual content is perceived to contribute to persistence of inequitable norms, especially in depicting women as submissive and men being sex driven [33]. In another study in a subset of these VYAs, we found inequitable sexual socialization tendencies beginning to emerge in early adolescence [25]. Both of these studies highlighted the role that media can play in shaping VYAs ideas about sex and relationships including norms that can be harmful to both boys and girls.

Schools and parents could serve as valuable resources for adolescents in mitigating potential harm of misleading media sources. One study in Uganda found that parents were in fact effective in mediating the effects of inappropriate media use among their adolescent children [34]. Furthermore, the National Sexuality Education Framework released by the Ugandan Ministry of Education and Sports includes modules on analyzing SRH information in the media [14]. Though this framework has not yet been implemented, it may enable schools to help students identify which information sources are accurate and credible, and which sources are not.

While the majority (95.1\%) of VYAs were aware of HIV, few were aware of the four most common ways that HIV is transmitted and over a third said that it is not possible for a person who looks healthy to have HIV. Similar findings about SRH knowledge were earlier described by Bankole et al., 2007 [23]. This shows that despite the extremely high level of HIV awareness, adolescents had inadequate in-depth knowledge on HIV transmission. Furthermore, only one third knew any STI other than HIV. This implies that they may not be equipped with sufficient information to protect themselves from acquiring HIV and other STIs. Knowledge of contraceptive methods was moderate, with just over half mentioning abstinence or modern methods. Inadequate contraceptive knowledge may lead to poor utilization of these methods. This is supported by a previous study among sexually active adolescents that found that contraceptive knowledge and uptake has been significantly lower in younger women compared to older women $[35,36]$. Clearly there are significant gaps in the information that young people are receiving about SRH. It is important that VYAs are aware of the health risks involved in sexual activity beyond HIV.

In this study, $7.6 \%$ of VYAs were sexually active, which is lower than previous findings among the same age group in Sub-Saharan Africa of 11-15\% [23, 37]. More boys than girls reported being sexually active, which may relate to underreporting among Ugandan girls, who are often less comfortable and more stigmatized for being

Table 4 Description of sexual behavior of Very Young Adolescents by gender

\begin{tabular}{|c|c|c|c|c|c|}
\hline Characteristic & Total & Male & Female & chi & $p$ value \\
\hline Ever went in seclusion with friend of opposite sex & $165(15.1)$ & $101(22.0)$ & $64(10.1)$ & 29.29 & $<0.001$ \\
\hline Have (been) kissed & $34(3.1)$ & $26(5.7)$ & $8(1.3)$ & 4.20 & 0.04 \\
\hline Have (been) fondled & $115(10.5)$ & $80(17.4)$ & $35(5.5)$ & 11.15 & $<0.001$ \\
\hline Had penetrative sex & $83(7.6)$ & $67(14.6)$ & $16(2.5)$ & 26.78 & $<0.001$ \\
\hline Used condoms on the last sexual experience (among sexually active only) & $8(9.6)$ & $7(10.4)$ & $1(6.7)$ & 0.26 & 0.61 \\
\hline Have no sexual experience but are under pressure to have it & $114(10.4)$ & $69(15.0)$ & $45(7.1)$ & 26.00 & $<0.001$ \\
\hline
\end{tabular}


sexually active before marriage [25]. However, it was noted in this study that the majority of sexually active young adolescents did not use condoms, which puts young adolescents at risk of STIs, HIV and early pregnancy. These findings are supported with an established association that early sexual debut is a risk factor for risky sexual practices in Uganda [38, 39]. Furthermore, recent evidence shows that adolescents especially those of better social economic background globally experience puberty at a younger age $[10,40,41]$. Simultaneously, they are choosing to get married later than previous generations [9]. Attainment of biological maturity much earlier than socioeconomic independence and marriage imposes a wider biosocial gap among adolescents that may expose them to sexual and reproductive health risks prior marriage [42].

Furthermore, because the majority of these students are still not sexually active, this is an opportune age to implement behavioral SRH interventions. A plethora of studies in low and middle income countries have shown that comprehensive SRH education is associated with delayed sexual onset [15, 43], but these programs can only delay sexual onset if they are implemented before target students are sexually active. Additionally, about $96 \%$ of Ugandan children attend some primary school, while only $34 \%$ go on to secondary education [44]. If SRH interventions only target secondary school students, the majority of Ugandan adolescents will miss out on this vital information. By targeting VYAs in primary school, SRH interventions can reach the majority of Ugandan adolescents with accurate information before they become sexually active. This study highlights the vital need for comprehensive, school-based SRH education for VYAs that will enable young people make informed decisions about their sexual health.

\section{Study limitations}

Sexual behavior was self-reported and this being a sensitive subject, under reporting could have occurred among some participants. During data collection, we ensured privacy and tried as much as possible to have interviewers of the same sex as respondents conduct the interviews in an effort to limit reporting bias, a form of information bias. While dichotomizing certain variables was helpful in demonstrating statistical results, this may have led to a loss of relevant data. Furthermore, because this was a cross sectional survey, we could not determine the direction of causality. Finally, due to cultural and legal restrictions around homosexuality in Uganda, we were only able to ask students about heterosexual behavior, and did not ask about homosexual activity.

\section{Conclusion}

Very young adolescents in Uganda face great challenges in SRH, having low SRH knowledge, early sexual debut and risky sexual practices. SRH education should start during early adolescence, before the majority of these students are sexually active and while most of them are still in school. Comprehensive, accurate, school-based SRH education is crucial. Further research should be conducted and used by policy makers in the development of nation-wide policies regarding SRH education for VYAs.

\section{Acknowledgements}

We would like to thank the study participants and all the research assistants and data management team for their contribution to the study.

\section{Funding}

Funding was obtained from VLIR-OUS for implementation of a team project between universities in Uganda and Belgium Mbarara (reference ZEIN2015PR411). The funders had no role in the study design, data collection, analysis or interpretation of data. The funders had no role in writing of the manuscript.

\section{Availability of data and materials}

The datasets used and/ or analyzed during this study are available from the corresponding author on reasonable request.

\section{Authors' contributions}

EK participated in design, data analysis and writing of the initial manuscript. $\mathrm{KB}$ participated in the data analysis, writing and editing of the initial manuscript. KM and VNN participated in data analysis and manuscript editing. GNR, WM, ABN, GC and EL participated in editing of the manuscript. All authors read and approved the final manuscript.

\section{Ethics approval and consent to participate}

We obtained institutional ethical approval from Mbarara University of Science and Technology in Uganda, reference MUIRC 1/7, the Uganda National Council of Science and Technology (reference SS 4045) and Ghent University in Belgium. Written consent from head teachers of participating schools, parents and assent from pupils were obtained prior data collection.

Consent for publication

Not applicable (we have not included names, images or videos that need obtaining of consent).

Competing interests

The authors declare that they have no competing interests.

\section{Publisher's Note}

Springer Nature remains neutral with regard to jurisdictional claims in published maps and institutional affiliations.

\section{Author details}

${ }^{1}$ Mbarara University of Science and Technology, P.O. Box 1410, Mbarara, Uganda. ${ }^{2}$ International Centre for Reproductive Health, Faculty of Medicine and Health Sciences, Ghent University, Ghent, Belgium. ${ }^{3}$ RHEA, Centre of Expertise on Gender, Diversity and Intersectionality, Vrije Universiteit Brussel, Brussels, Belgium.

Received: 22 March 2018 Accepted: 21 August 2018

Published online: 29 August 2018

References

1. CIA. The World Fact Book 2017 [21 Mar 2018]. Available from: https://www. cia.gov/library/publications/the-world-factbook/fields/2177.html. Accessed 21 Mar 2018. 
2. Uganda Bureau of Statistics [UBOS]. National Population and Housing Census 2014, Provisional Results. Kampala, Uganda: UBOS. 2014. Retrieved from http:// library.health.go.ug/publications/leadership-andgovernance-monitoring-andevaluation/population/national-population-an-0. Accessed 10 June 2018.

3. Uganda Bureau of Statistics [UBOS], \& ICF International. (2017). Uganda Demographic Health Survey 2016: Key Indicators Report. Kampala, Uganda: UBOS, and Rockville, Maryland,USA: UBOS and ICF International. Retrieved from https://www.ubos.org/onlinefiles/uploads/ubos/pdf\%20documents/ Uganda_DHS_2016_KIR.pdf. Accessed 20 Feb 2018.

4. CIA. The World Fact Book, Country Comparison HIV/AIDS Adult prevalence rate 2016 [27th February 2018]. Available from: https://www.cia.gov/library/ publications/resources/the-world-factbook/rankorder/2155rank.html. Accessed 27 Feb 2018

5. UPHIA(2016-2017). Uganda Population Based HIV Impact Assessment 2017 [21 June 2018]. Available from: http://www.afro.who.int/sites/default/files/ 2017-08/UPHIA\%20Uganda\%20factsheet.pdf. Accessed 21 June 2018.

6. Green EC, Halperin DT, Nantulya V, Hogle JA. Uganda's HIV prevention success: the role of sexual behavior change and the national response. AIDS Behav. 2006;10(4):335-46.

7. Institute for health metrics and evaluation; [27th February 2018]. Available from: http://www.healthdata.org/uganda. Accessed 27 Feb 2018.

8. Boosey R, Prestwich G, Deave T. Menstrual hygiene management amongst schoolgirls in the Rukungiri district of Uganda and the impact on their education: a cross-sectional study. Pan Afr Med J. 2014;19:253.

9. Bello BM, Fatusi AO, Adepoju OE, Maina BW, Kabiru CW, Sommer M, et al. Adolescent and parental reactions to puberty in Nigeria and Kenya: a crosscultural and intergenerational comparison. J Adolesc Health. 2017;61(4):S35-41.

10. Mehra D, Agardh A, Odberg Petterson K, Östergren P-O. Non-use of contraception: determinants among Ugandan university students. Glob Health Action. 2012;5(1):18599.

11. Mehra D, Östergren P-O, Ekman B, Agardh A. Inconsistent condom use among Ugandan university students from a gender perspective: a crosssectional study. Glob Health Action. 2014;7(1):22942.

12. Annah $\mathrm{N}$. The sex education debate has been blown out of proportion UNFPA 2016 [20 June 2018]. Available from: http://capitalradio.co.ug/sexeducation-debate-blown-proportion-unfpa/. Accessed 20 June 2016.

13. Time to lift the ban on se education in schools [press release]. Kampala, Uganda 2017. http://www.monitor.co.ug/News/Education/Time-to-lift-banon-sex-education-in-schools/688336-4007894-mm27t8z/index.html. Accessed 20 June 2018.

14. Ministry-of-Education-and-Sports-Uganda. National Sexuality Education Framework https://www.education.go.ug/files/downloads/UNFPA_68_ 090518.pdf: 2018. Accessed 20 June 2016.

15. Fonner VA, Armstrong KS, Kennedy CE, O'Reilly KR, Sweat MD. School based sex education and HIV prevention in low-and middle-income countries: a systematic review and meta-analysis. PLoS One. 2014;9(3):e89692.

16. UNESCO, UNAIDS, UNFPA, UN Women and WHO, (2018). International Technical Guidance on Sexuality Education, an evidence-informed approach, revised edition. Retrieved from http://unesdoc.unesco.org/ images/0026/002607/260770e.pdf. Accessed 20 June 2018.

17. $\mathrm{WHO} / \mathrm{RHR} / 11.11$. The sexual and reproductive health of young adolescents in developing countries. Geneva: research DoRHa; 2010. http://apps.who.int/ iris/bitstream/10665/70569/1/WHO_RHR_11.11_eng.pdf

18. Igras SM, Macieira M, Murphy E, Lundgren R. Investing in very young adolescents' sexual and reproductive health. Global Public Health. 2014;9(5):555-69.

19. Blum RW, Astone NM, Decker MR, Mouli VC. A conceptual framework for early adolescence: a platform for research. Int J Adolesc Med Health. 2014;26(3):321-31.

20. Fearon $E$, Wiggins RD, Pettifor $A E$, Hargreaves JR. Is the sexual behaviour of young people in sub-Saharan Africa influenced by their peers? A systematic review. Soc Sci Med. 2015;146:62-74.

21. Albert B, Brown S, Flanigan CM. 14 years and younger: The sexual behavior of young adolescents. Washington: National Campaign to Prevent Teen Pregnancy; 2003.

22. Ministry of Education and Sports, (2018). National Sexuality Education Framework 2018. Kampala, Uganda: Ministry of Education and Sports. Retrieved from https://www.education.go.ug/files/downloads/ NATIONAL\%20SEXUALITY\%20EDUCATION\%2OFRAMEWORK.pdf. Accessed 21 June 2018.

23. Bankole A, Biddlecom A, Guiella G, Singh S, Zulu E. Sexual behavior, knowledge and information sources of very young adolescents in four sub-Saharan African countries. Afr J Reprod Health. 2007;11(3):28.
24. Kemigisha E, Nyakato VN, Bruce K, Ndaruhutse Ruzaaza G, Mlahagwa W, Ninsiima AB, et al. Adolescents' sexual wellbeing in southwestern Uganda: a cross-sectional assessment of body image, self-esteem and gender equitable norms. Int J Environ Res Public Health. 2018;15(2):372.

25. Ninsiima AB, Leye E, Michielsen K, Kemigisha E, Nyakato VN, Coene G. "Girls have more challenges; they need to be locked up": a qualitative study of gender norms and the sexuality of young adolescents in Uganda. Int J Environ Res Public Health. 2018;15(2):193.

26. Mbarara District Education Office. Report on Schools and enrollment in Mbarara District, (2015). Unpublished data.

27. Darabi L, Bankole A, Serumaga S, Neema S, Kibombo R, Banoba P et al. Protecting the next generation in Uganda: new evidence on adolescent sexual and reproductive health needs (2008). Retrieved from https://www. guttmacher.org/sites/default/files/report_pdf/png_uganda_mono.pdf. Accessed 20 June 2018

28. Bar-on ME, Broughton DD, Buttross S, Corrigan S, Gedissman A, de Rivas MG, et al. Sexuality, contraception, and the media. Pediatrics. 2001;107(1):191-4.

29. Hust SJ, Brown JD, L'Engle KL. Boys will be boys and girls better be prepared: an analysis of the rare sexual health messages in young adolescents' media. Mass Commun Soc. 2008;11(1):3-23.

30. Bull SS, Levine DK, Black SR, Schmiege SJ, Santelli J. Social media-delivered sexual health intervention: a cluster randomized controlled trial. Am J Prev Med. 2012;43(5):467-74

31. Straight Talk Foundation, (2017). Straight Talk Annual report 2017. Retrieved from http://straighttalkfoundation.org/index.php/resources/annual-reports/ 55-annual-report-2017/file. Accessed 21 June 2018.

32. Mulugeta $Y$, Berhane $Y$. Factors associated with pre-marital sexual debut among unmarried high school female students in bahir Dar town, Ethiopia: cross-sectional study. Reprod Health. 2014;11(1):40.

33. Miller AN, Nalugya E, Gabolya C, Lagot S, Mulwanya R, Kiva J, et al. Ugandan adolescents' sources, interpretation and evaluation of sexual content in entertainment media programming. Sex Educ. 2016;16(6):707-20.

34. Miller AN, Gabolya C, Mulwanya R, Nabaseke G, Kiva J, Nalugya E, et al. The relationship between parental mediation of adolescent media use and Ugandan Adolescents' sexual attitudes and behavior. Howard J Commun. 2017:1-14.

35. Dennis ML, Radovich E, Wong KL, Owolabi O, Cavallaro FL, Mbizvo MT, et al. Pathways to increased coverage: an analysis of time trends in contraceptive need and use among adolescents and young women in Kenya, Rwanda, Tanzania, and Uganda. Reprod Health. 2017;14(1):130.

36. Wolf HT, Teich HG, Halpern-Felsher BL, Murphy RJ, Anandaraja N, Stone J, et al. The effectiveness of an adolescent reproductive health education intervention in Uganda. Int J Adolesc Med Health. 2017;29(2)

37. Wellings $K$, Collumbien M, Slaymaker E, Singh S, Hodges Z, Patel D, et al. Sexua behaviour in context: a global perspective. Lancet. 2006;368(9548):1706-28.

38. Mbalinda SN, Kiwanuka N, Eriksson LE, Wanyenze RK, Kaye DK. Correlates of ever had sex among perinatally HIV-infected adolescents in Uganda. Reprod Health. 2015;12:96

39. Mmari KN, Kaggwa E, Wagman J, Gray R, Wawer M, Nalugoda F. Risk and protective correlates of young women's first sexual experiences in Rakai, Uganda. Int Perspect Sex Reprod Health. 2013;39(3):153-62.

40. Sidze EM, Elungata'a P, Maina BW, Mutua MM. Does the quality of parent-child connectedness matter for adolescents' sexual behaviors in Nairobi informal settlements? Arch Sex Behav. 2015;44(3):631-8.

41. Kabiru CW, Mumah JN, Maina BW, Abuya BA. Violence victimisation and aspirations-expectations disjunction among adolescent girls in urban Kenya. Int J Adolesc Youth. 2017:1-10.

42. Fathalla MF. Global trends in women's health. International Journal of Gynecology \& Obstetrics. 1997;58(1):5-11.

43. Kirby DB. The impact of abstinence and comprehensive sex and STD/HIV education programs on adolescent sexual behavior. Sex Res Soc Policy. 2008;5(3):18-27.

44. Uganda Bureau of Statistics [UBOS], \& ICF International. (2012). Uganda Demographic and Health Survey 2011. Kampala, Uganda: UBOS and ICF International. Retrieved fromhttps://www.ubos.org/onlinefiles/uploads/ubos/ UDHS/UDHS2011.pdf. Accessed 20 Feb 2018. 